\title{
$\mathrm{RT}$ 미들웨어와 고속 네트워크 기술을 이용한 시스템 통합에 관한 연구
}

\section{A Study on System Integration using RT-Middleware and High Speed Network}

\author{
문용선 · 트롱루안 · 이영필* · 박종규** · 배영철** \\ Yongseomn Moon, Vo Trong Tuan Anh, Youngpil Lee*, Jong Kyu Park** and Youngchul Bae** \\ 순천대학교/레드원테크놀러지, "레드원테크놀러지, " ${ }^{*} \mathrm{KISTI}$, 전남대학교 \\ 요 약 \\ 본 논문에서는 고속의 이더넷 네트워크 기술을 이용한 하드웨어 통합 기술과 RT 미들웨어를 이용한 소프트웨어 통합 기 \\ 술을 적용한 친환경 스마트 가전 기기들을 효과적으로 통합하고 운용하는 기술 방법에 대하여 제시한다. 또한 고속 이더 \\ 넷을 이용한 분산 하드웨어 장치들의 통합 및 $\mathrm{RT}$ 미들웨어 기술을 이용한 소프트웨어 통합 기술을 기술하고, 고속 이더 \\ 넷 기술과 RT 미들웨어 기술을 적용한 친환경 스마트 홈 가전기기의 통합 관리 시스템을 구현한다.
}

\begin{abstract}
In this paper, we propose effective integration and operation methods for environment-friendly smart home appliance which are applying hardware integration technology using high speed Ethernet network technology and software integration technology using RT middleware. We also describe the integration of distributed hardware device by using high speed Ethernet and software integration technology by using RT middleware. We implement the integration management system of environment-friendly smart home appliance applying high speed Ethernet and RT middleware technology.
\end{abstract}

Key Words : RT 미들웨어, 하드웨어 소프트웨어 통합, 통합관리시스템

\section{1. 서 론}

하드웨어 및 소프트웨어 시스템의 구현에 있어서의 최근 추세는 통합 기술이라 할 수 있다. 시스템 통합 기술이란 분 산된 하드웨어 및 소프트웨어 환경 등을 보다 쉽고 빠르게 하나의 시스템처럼 통합하여 운용할 수 있는 기술이라 할 수 있다.

하드웨어 시스템은 자동화 및 IT 기술 개발로 인하여 다양 한 장치들이 혼합적으로 사용되면서 대두되기 시작하였다. 이 는 서로 다른 기종 장치들의 사용 및 기기들의 독자적인 인터 페이스 구조로 인하여 상위 제어기에서 이러한 혼합된 시스템 을 적절하게 통합하여 사용하는 것에 어려움이 발생하였기 때 문이다. 최근에는 네트워크 기반 제어 시스템이 많이 적용되 면서부터 하드웨어 시스템의 통합에 있어 장치 및 시스템을 통합을 위한 최적의 네트워크를 선정이 핵심 요건 중에 하나 라고 할 수 있다. 최근에는 종래의 $1: 1$ 연결방식 및 저속의 필 드 버스 등의 네트워크 방식에서 산업용 이더넷 기반의 고속 의 제어용 네트워크 방식이 분산된 하드웨어 장치 및 시스템 을 통합하는데 최적의 솔루션으로 평가되고 있다. [1]

소프트웨어 시스템의 경우 기존에는 범용 코드 기반의 독

접수일자 : 2009년 11월 9일

완료일자 : 2009년 12월 30일

본 논문은 스마트친환경 가전사업에 의해 지원에 의해 수행되었음.
자적인 소프트웨어 개발 환경(C, Basic, Java 등)에서 미들웨 어를 기반으로 하는 통합 소프트웨어 환경을 기반으로 하는 컴포넌트 기반의 통합 소프트웨어 개발 환경이 성세를 이루고 있다. 이는 기존의 코드 기반 프로그램의 복잡한 시스템 구현 에 있어서의 시간적인 소모와 소프트웨어들 간의 호환성 등의 문제 등으로 인하여 사용상에 한계가 있었기 때문이다. 이에 최근에는 공용으로 적용할 수 있는 표준화된 통합 미들웨어 플랫폼을 기반으로 한 컴포넌트 기반의 개발 방식을 사용함으 로서 소프트웨어의 재사용성 및 호환성을 극대화 하였다.

이에 본 논문에서는 고속의 이더넷 네트워크 기술을 이용 한 하드웨어 통합 기술과 RT 미들웨어를 이용한 소프트웨어 통합 기술을 적용한 친환경 스마트 가전 기기들을 효과적으 로 통합하고 운용하는 기술 방법에 대하여 제시한다. 고속 이더넷을 이용한 분산 하드웨어 장치들의 통합 및 RT 미들 웨어 기술을 이용한 소프트웨어 통합 기술을 기술하고, 고속 이더넷 기술과 RT 미들웨어 기술을 적용한 친환경 스마트 홈 가전기기의 통합 관리 시스템을 구현한다.

\section{2. 고속 이더넷 통신을 이용한 하드웨어 시스템 통합}

최근 분산된 하드웨어 장치 및 시스템을 통합하여 운용하 기 위한 솔루션으로서 고속 이더넷 네트워크 기반의 시스템 
통합 기술이 대두되고 있다. 이는 기존에 사용되었던 무선 인터페이스를 이용한 통합 시스템 운용의 경우 무선 통신의 비결정적인 특성으로 인하여 정확한 제어가 어려웠으며, 또 한 종래에 사용되었던 저속의 버스 연결 방식의 구조 역시 처리속도 및 동기화 문제에 결함을 가지고 있어 이를 대체하 는 방법으로서 고속의 제어용 이더넷을 이용한 방식이 효과 적인 대안으로 평가되었기 때문이다.

네트워크 기반 시스템에서 분산된 다양한 기기들을 효과 적으로 통합하여 운용 및 제어하기 위해서는 기본적으로 고 수준의 통신 속도를 만족해야 한다. 이러한 시스템 통합의 관점에서 이더캣 통신은 그림 1 의 비교에서 알 수 있듯이 다 른 제어용 이더넷 기반의 통신에 비해 상당한 강점을 가지고 있다. [2-4]

시스템 통합을 위해 적합한 네트워크의 또 다른 조건으로 는 연결 및 배선이 쉬워야 한다. 그러나 기존의 이더넷 기반 의 통신 방식들의 경우 스타형의 구조를 지향하고 있어 그림 2 와 같이 시스템의 크기가 증가할수록 배선의 복잡도가 증가 하게 되는 단점을 가지고 있다.

그러나 이더캣 기반의 통합 시스템의 구조 스타, 라인, 트 리 구조 등 다양하고 유연한 연결 방식을 제공하고 있어 시 스템 통합에 유리한 강점을 가지 수 있게 된다. [2-4]

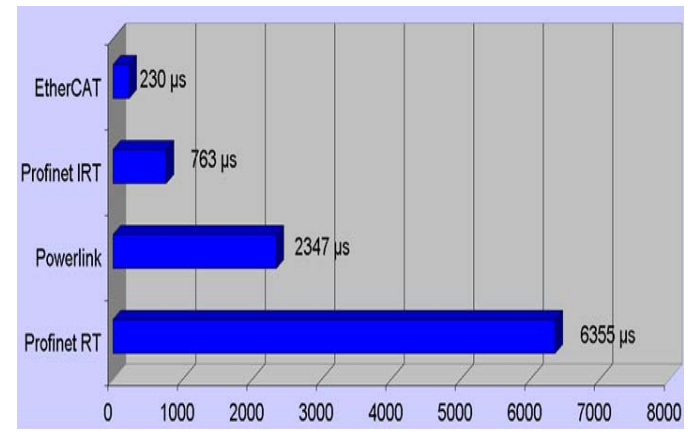

그림 1. 제어용 이더넷 기반의 통신 프로토콜 들 간의 통신 사 이클 타임 비교

Fig.1 Comparison of communication cycle time between communication protocol based on control Ethernet

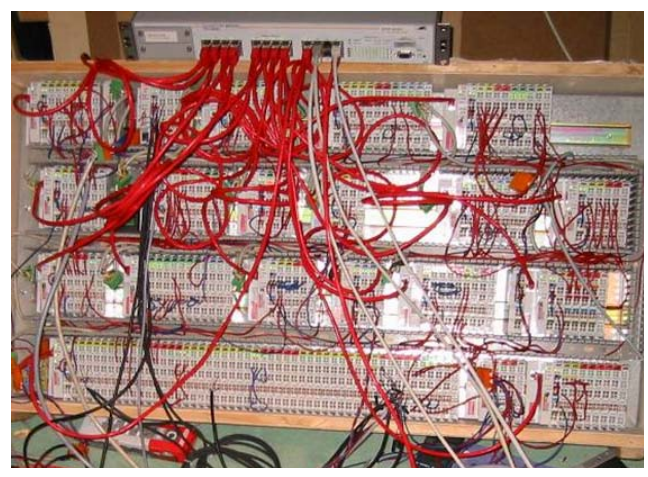

그림 2. 기존의 이더넷 기반의 시스템 연결 및 배선 구조

Fig.2 System connect and wiring structure based on previous Ethernet

이 외에도 네트워크 기반 분산된 기기들을 운용함에 있어
장치들 간의 동작을 일치시키는 동기화 성능에 있어서도 이 더캣 통신은 상당한 장점을 가지고 있다. [2-4]

그림 3에 이더캣 기반의 시스템 연결 및 배선 구조를 나타 내었다. 그림 3 의 이더캣 기반의 시스템 연결 및 배선 구조 는 기존 이더넷 기반의 방식에 비해 배선 구조가 간단하여 배선으로 인한 문제점을 해결할 수 있는 장점을 가진다.

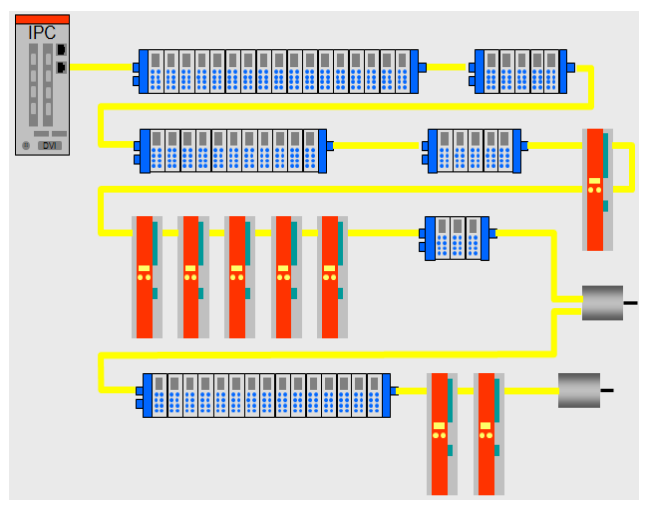

그림 3. 이더캣 기반의 시스템 연결 및 배선 구조

Fig.3 System connect and wiring structure based on Ethernet

그림 4에 이더캣을 적용한 시스템의 동기화 성능을 나타 내었다. 각 $120 \mathrm{~m}$ 의 노드 사이에 접속된 300 개의 노드(네트 워크 디바이스) 들을 대상으로 실시한 동기 스위칭 파형의 성능을 나타내며 결과를 통하여 알 수 있듯이 $+-15 \mathrm{~ns}$ 의 정 밀성을 보이며, 이는 동기화 기준 척도인 $1 \mathrm{us}$ 를 훨씬 상회하 는 성능이므로 매우 우수하다고 할 수 있다.

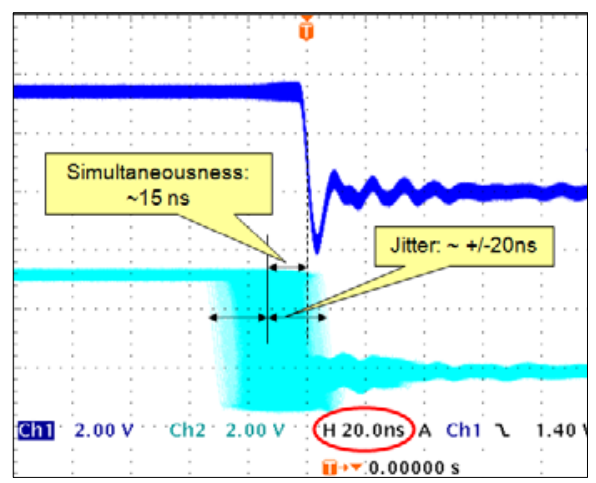

그림 4. 수십 $\mathrm{ns}$ 레벨의 이더캣 동기화 성능

Fig. 4 EtherCAT synchronization performance of a few ns level

\section{RT 미들웨어 기술을 이용한 소프트웨어 통합}

하드웨어 통합 기술이 고속 이더넷을 이용한 네트워크 기 반 통합 시스템의 구조를 지향해 가고 있는 반면 하드웨어를 운용 및 관리하는 소프트웨어 기술은 미들웨어 기반의 컴포 넌트형 구조가 소프트웨어 통합 기술로서 연구 및 개발되고 있다. 이러한 소프트웨어 통합을 위해 개발된 프레임워크로 
는 MSRDS, iRSP, OpenRTM 등이 있다. 본 연구에서는 이 중에서도 실시간 환경에서 보다 강력한 성능을 발휘하는 것 으로 평가되는 CORBA 기반의 OpenRTM 기술을 이용하여 그 구현 방법을 연구하였다.

OpenRTM 기술은 실제 하드웨어와 사전에 가상으로 매 핑된 RTC(RT Component)라는 소프트웨어 컴포넌트를 이 용한다. RT 컴포넌트들은 네임서버라 불리는 서버에 업로드 되어 운영이 되므로 하드웨어 및 제어 플랫폼과 독립적인 운 용이 가능하다. 즉, 서로 다른 운용환경 및 제어 플랫폼 에서 개발된 RT 컴포넌트라 할지라도 동일한 네임서버를 사용함 으로서 하나의 제어 플랫폼 상에서 다른 환경에서 개발된 RT 컴포넌트들의 수집 및 사용이 가능하게 된다. OpenRTM 기반의 소프트웨어 통합 계층에 대한 구조는 그 림 5 와 같다.

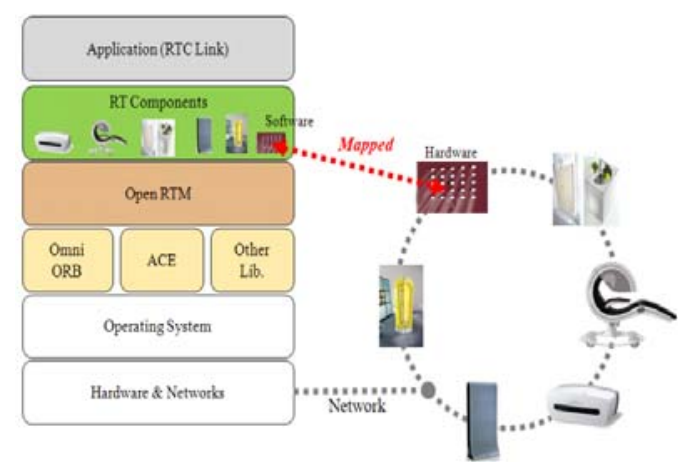

그림 5. OpenRTM 기반의 소프트웨어 통합 아키텍처 Fig. 5 OpenRTM based on software integration archic ${ }^{-}$ ture

\section{4. 하드웨어 및 소프트웨어 통합 시스템 구현}

본 연구에서는 RT 미들웨어 기술과 고속 네트워크를 이 용한 시스템 통합 기술을 구현하였으며 이를 친환경 스마트 홈 가전기기 (Home application)에 적용하였다. 친환경 스마 트 홈 가전기기에 대한 하드웨어 및 소프트웨어 통합 시스템 구현 과정은 다음과 같다. [5][6]

\section{1. 고속 네트워크 기반 친환경 스마트 홈 가전기기 하드웨어 통합 구현}

시스템 구현을 위해 사용된 친환경 스마트 홈 가전기기들 의 하드웨어 통합을 위하여 공용의 네트워크를 이용한 네트 워크 기반 시스템 통합 구조를 적용하였으며 이를 그림 6에 나타내었다.

그림 6 과 같은 시스템 구현을 위하여 각각 분산된 가전 기 기들은 $100 \mathrm{Mbps}$ 급의 고속 제어용 이더넷을 통하여 시리얼 형태로 연결되었으며, 각 가전 기기들의 네트워크 접속을 위 하여 네트워크 인터페이스 모듈을 제작하였다.

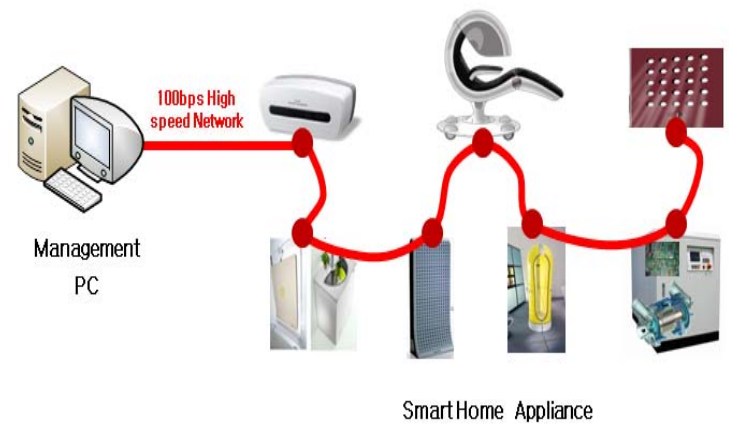

그림 6. 고속 네트워크 기반의 친환경 스마트 홈 가전기기 통합 네트워크 시스템 구조

Fig. 6 Structure of high speed network based on environment-friendly smart home appliance integration network system

\subsection{RT 미들웨어 기반 친환경 스마트 홈 가전기기 소 프트웨어 통합 구현}

하드웨어 시스템 통합이 완료되면 RT 미들웨어 기술을 이용하여 친환경 스마트 홈 가전기기를 운용하는 소프트웨어 환경을 통합하는 과정을 수행한다. 소프트웨어 통합 방법은 CORBA 기반의 RT 미들웨어 기술(Open RTM)을 적용함으 로서 제어 플랫폼과 유무선 환경에 무관한 통합 인터페이스 환경을 구축하며, 이러한 환경 내에서 제작된 RT 미들웨어 컴포넌트 (RT Components)를 서버 상에서 수집 및 재구성 함으로서 시스템을 운용 및 제어할 수 있는 방법을 적용하였 다. 유무선 및 분산 시스템 간의 RT 미들웨어 기술을 이용 한 소프트웨어 통합에 대한 세부적인 구조는 그림 7 과 같다.

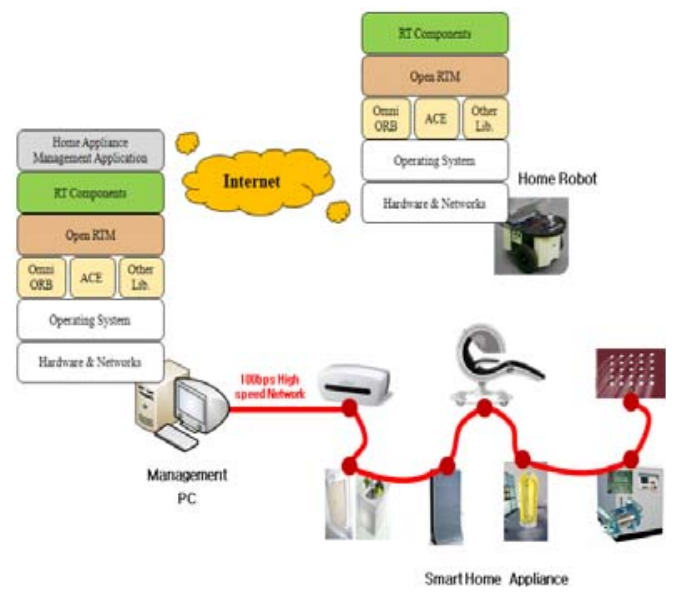

그림 7. RT 미들웨어 기술을 이용한 친환경 스마트 홈 가전 기기의 소프트웨어 통합 구조

Fig. 7 Structure of software integration of environment-friendly smart home appliance using RT middle technologies

\subsubsection{RT 미들웨어 컴포넌트 구현}

소프트웨어 인터페이스 통합을 위하여 통합된 RT 미들웨 어 환경 내에서 실행될 친환경 스마트 홈 가전기기용 표준 RT 컴포넌트를 그림 8과 같이 구현하였다. 


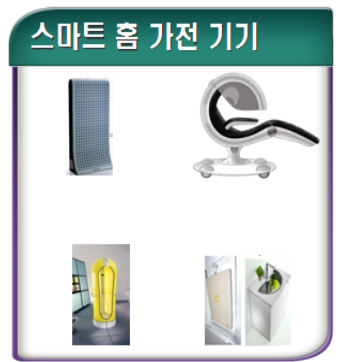

〈하드웨어 >

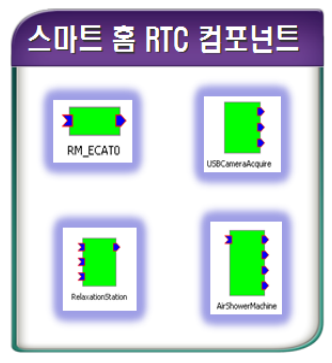

〈소프트웨어〉
그림 8. 친환경 스마트 홈 가전기기용 RT 컴포넌트

Fig. 8 RT middleware for environment-friendly smart home appliance

실제 구현한 RT 컴포넌트 내역은 표 1 과 같다.

표 1. 친환경 스마트 홈 가전 기기용 RT 컴포넌트

Table 1. RT component for environment-friendly smart home appliance

\begin{tabular}{|c|c|}
\hline RTC 컴포넌트 내역 & 기능 \\
\hline Air Shower Machine & 공기를 이용한 샤워 장치 \\
\hline Happy Feet & 항균 신발 거치대 \\
\hline Home Robot & 홈 관제 로봇 \\
\hline Air Bed & 공기를 이용한 친환경 침대 \\
\hline Air Washing Machine & 공기를 이용한 살균 세탁기 \\
\hline Relaxation Station & 공기를 이용한 안락 의자 \\
\hline
\end{tabular}

\section{3. 통합 친환경 스마트 홈 가전 시스템 운용 태스크} 생성 및 실행

친환경 스마트 홈 가전기기에 대한 RT 컴포넌트의 개발 이 완료되면 개발된 그림 9 와 같이 RT 컴포넌트를 이용한 친환경 스마트 홈 관리용 태스크를 개발하고 이를 가동하여 시스템을 운용 및 제어하면 된다.

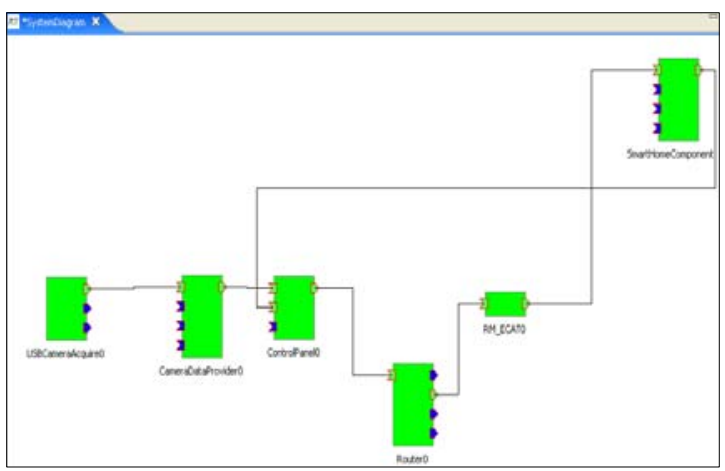

그림 9. RT 컴포넌트를 이용한 친환경 스마트 가전 시스템 운용 태스크

Fig. 9 Operation task of environment-friendly smart home appliance using RT component
본 논문에서 제작한 RT 컴포넌트 기반의 친환경 스마트 홈 가전기기 동작 태스크를 실행하면 그림 10과 같은 사용 자 인터페이스 창이 실행되며 각각의 홈 가전 기기들에 대한 동작 및 상태 정보를 모니터링 할 수 있다.

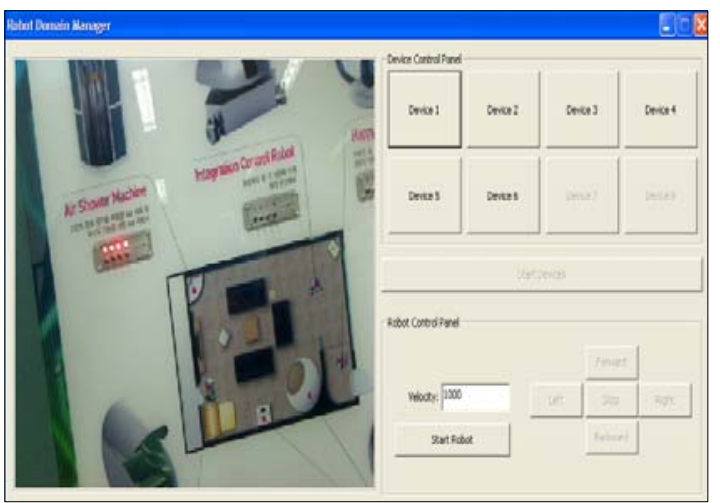

그림 10. 하드웨어 및 소프트웨어 통합된 친환경 스마트 홈 가전기기 용 동작제어 테스트 어플리케이션

Fig. 10 Hardware and software integrated test application of operation control for environment-friendly smart home appliance

그림 11은 Air Shower Machine에 대한 상태 모니터링 정보를 나타낸다.

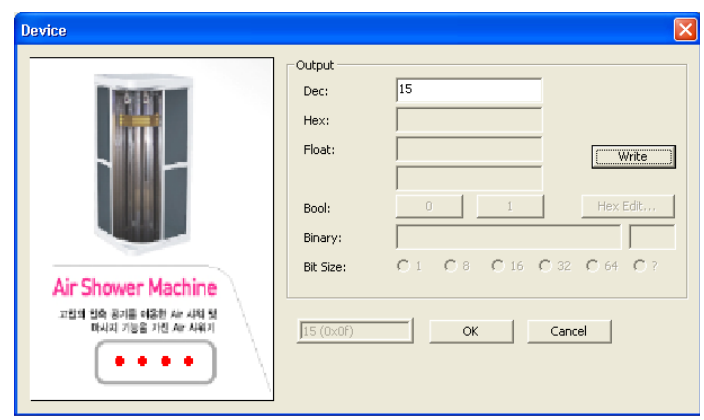

그림 11. 친환경 스마트 홈 가전기기 상태 정보 모니터링

Fig. 11 State information monitoring of environment-friendly smart home appliance

\section{5. 결 론}

본 논문은 최근 분산 자동화 시스템의 핵심 기술 중에 하 나로서 평가되는 시스템 통합 기술에 대한 연구로서 고속의 제어용 이더넷을 이용한 분산 기기들의 하드웨어 시스템의 통합과 미들웨어 기반의 소프트웨어 통합 기술에 대하여 기 술하였다.

하드웨어 시스템 통합 기술은 최근 로봇 및 자동화 시스 템 등에서 통합 네트워크로서 큰 관심을 받고 있는 이더캣 통신을 이용하였으며, 소프트웨어 통합 기술은 실시간 환경 에 비교적 강건하다고 평가되는 $\mathrm{CORBA}$ 기반 RT 미들웨어 기술을 이용한 컴포넌트 형 소프트웨어 통합 기술과 시스템 구현에 대하여 기술 하였다.

통합 시스템 구현은 친환경 스마트 가전기기를 대상으로 하드웨어 및 소프트웨어 통합 시스템을 구현하였다. 실제 
가전 기기들의 모두 개발되어 있는 상태가 아니므로 시뮬레 이터 시스템을 중심으로 구현을 하였으며, 실험 결과 우수한 구동 결과를 얻을 수 있었다.

앞으로 실제 하드웨어로 구현된 친환경 스마트 가전기기 를 대상으로 통합 시스템을 지속적으로 검증하는 것이 과제 로 남는다. 또한 본 논문에서 다루지 못한 다양한 통합 네트 워크와 미들웨어 기술을 적용한 통합 시스템을 구현함으로서 각 기술들의 장단점을 종합적으로 분석하는 것이 필요하다.

\section{참 고 문 헌}

[1] 국제 표준화 협회 “OMG Robotics DTF”, 2007

[2] EtherCAT Technology Group,

"EtherCAT Specification V1.0", 2004.

[3] Beckhoff, "EtherCAT Slave Controller (ESC10/20 Hardware Data Sheet)", 2005.

[4] EtherCAT Technology Group, "EtherCAT Communicatin", 2007.

[5] OPENRTM Document "http://www.openrtm.org/"

[6] Slovakian-Hungarian Joint Symposium on Applied Machine Intelligence and Informatics, "Virtual Master Device", 2007.

[7] 문용선, 이광석, 서동진, 이성호, 배영철, “모듈 로봇 구현을 위한 모터 제어 드라이버 개발” 퍼지 및 지능 시스템학회 논문지, 17권 7호, pp. 887-892. 2007.

[8] 문용선,이영필, 서동진,이성호, 배 영철, "EtherCAT 을 이용한 소프트 모터 제어기 개발에 관한 연구”, 퍼지 및 지능시스템학회 논문지, 17 권 6호, $\mathrm{pp}$. 826-831.2007

\section{저 자 소 개}

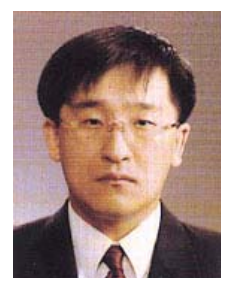

문용선 (文庸善)

1983년 2월 : 조선대학교 전자공학과 (공학사)

1989년 2월 : 조선대학교 대학원 전자 공학과(공학박사)

1992년 현재 : 순천대학교 정보통신공학부 교수/레드원테크놀러지(주) 기술이사

관심분야: 산업통신망 및 로봇, 실시간 모션 제어

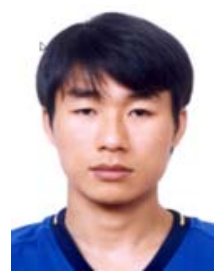

이영필(李榮必)

2006년 2월 : 순천대학교 전자공학과 (공학사)

2008년 2월 : 순천대학교 전자공학과 (공학석사)

2008년 현재 : 레드원테크놀러지(주) 연구원

관심분야: 로봇 제어, 모터 제어, 산업통신망

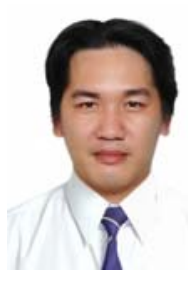

트롱루안(Vo Trong Tuan Anh)

2006년 9월 : Vietnam National University -Ho Chi Minh city University of Natural Sciences Information Technology

2008년 2월 : 순천대학교 전자공학과 (공학석사)

관심분야 : 로봇 제어, 모터 제어, 산업통신망

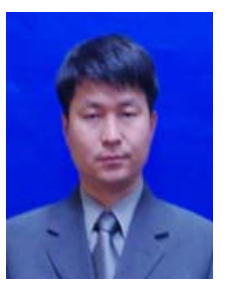

박종규(朴宗圭)

1984년 2월 : 중앙대학교 전자공학과 (공학사)

1990년 2월 : 중앙대학교 전자공학과 (공학석사)

1991년 현재 : 한국과학기술 정보연구원 선임연구원

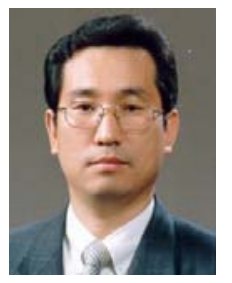

배영철(裴英哲)

1984년 2월 : 광운대학교 전기공학과 (공학사)

1986년 2월 : 광운대학교대학원 전기공학과(공학석사)

1997년 2월 : 광운대학교대학원 전기공학과(공학박사)

1986년 1991년 : 한국전력공사

1991년 1997년 : 산업기술정보원 책임연구원 1997년 2006년 : 여수대학교 전자통신전기공학부 부교수 2006년 현재 : 전남대학교 전기전자통신컴퓨터공학부 교수

관심분야: Chaos Control and Chaos Robot, Robot control etc. 